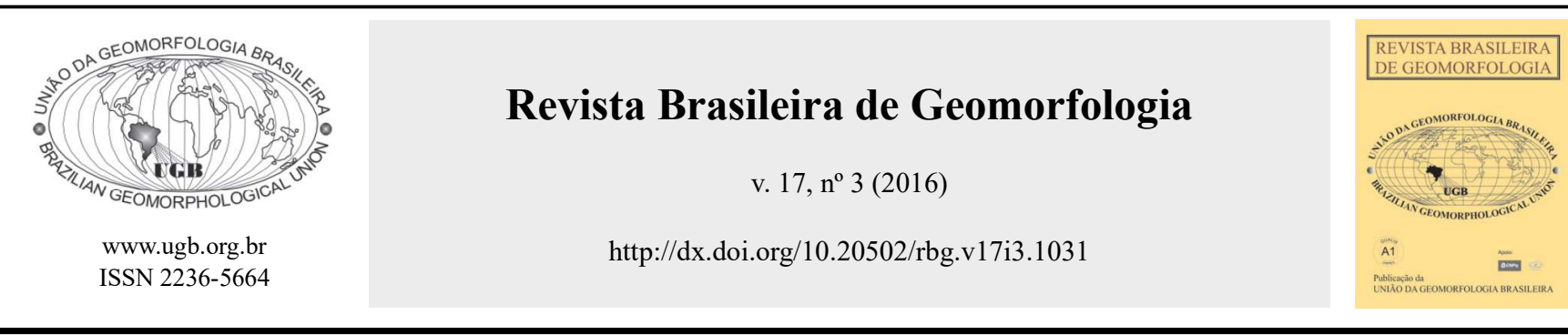

\title{
MEDITAÇÕES EM TORNO DA RELAÇÃO ENTRE ENGENHARIA HIDRÁULICA E GEOMORFOLOGIA FLUVIAL: BREVE APANHADO HISTÓRICO E APONTAMENTOS PARA NOVAS PESQUISAS
}

\author{
MEDITATIONS ON THE RELATIONSHIP BETWEEN HYDRAULIC \\ ENGINEERING AND FLUVIAL GEOMORPHOLOGY: BRIEF OVERVIEW \\ AND HISTORICAL NOTES FOR FURTHER RESEARCH
}

\author{
Roberto José Hezer Moreira Vervloet \\ Gerência de Recursos Naturais, Instituto Estadual de Meio Ambiente e Recursos Hídricos \\ BR 262, KM 0 s/n, Cariacica, Espírito Santo, CEP: 291402-61, Brasil \\ Email: rvervloet@usp.br
}

\section{Informações sobre o Artigo \\ Recebido (Received): \\ 12/03/2016 \\ Aceito (Accepted): \\ $12 / 06 / 2016$ \\ Palavras-chave: \\ Engenharia Hidráulica; \\ Geomorfologia Fluvial; História; \\ Epistemologia e Filosofia.}

\section{Keywords:}

Hydraulic Engineering; Fluvial Geomorphology; History; Epistemology and Philosophy.

\begin{abstract}
Resumo:
Este artigo trata de uma linha importante de reflexão epistemológica existente na história da geomorfologia fluvial: a da sua relação com a engenharia hidráulica e a hidrodinâmica. Ao estudarmos este ramo da geomorfologia percebemos como sua gênese histórica teve origem e foi dependente das discussões científicas e epistemológicas que houve no nascedouro da engenharia hidráulica e da hidrodinâmica fluvial. Desta forma, evidenciamos a tese de que o estágio de discussão estabelecido por engenheiros hidráulicos a partir da passagem do século XVII para o XVIII foi fundamental para o avanço dos conhecimentos e fundação das bases epistemológicas para a constituição das teorias fluviais sobre o relevo terrestre no início do século XIX (nascedouro da geomorfologia fluvial). Abre-se, desta forma, excelente campo para novas pesquisas e reflexões sobre a filosofia histórica desta disciplina.
\end{abstract}

\begin{abstract}
:
This article deals with an important line of existing epistemological reflection in the history of fluvial geomorphology: to its relationship with hydraulic engineering and hydrodynamics. We study this branch of geomorphology perceive as their historical genesis originated and was dependent on scientific and epistemological discussions that there was the birthplace of hydraulic engineering and river hydrodynamics. Thus, we highlight the view that the discussion stage set by hydraulic engineers from the passage of the seventeenth century to the eighteenth was instrumental in the advancement of knowledge and foundation of epistemological basis for the establishment of river theories on terrestrial relief in the early nineteenth century (initiation of fluvial geomorphology). It opens thus excellent ground for new research and reflections on the historical philosophy of this discipline.
\end{abstract}




\section{Introdução}

Meditar sobre os problemas teóricos e metodológicos da geomorfologia fluvial pressupõe algo mais do que simples inquirições geocientíficas. Na verdade, pressupõe não somente refletir sobre questões de método, teoria, técnica e escala de análise, mas reunir dentro de um contexto de experiência, aliado às opções de escolha, as concepções ofertadas conforme a época e objetivos da pesquisa que se almeja realizar. Deve-se admitir que todo um exercício de reflexão sustentada por uma determinada ótica de ciência, transparece aqui e acolá nas diversas linhas de pesquisa, fundamentado por linhas demagógicas e tratamentos ortodoxos que sempre ocorrem aliados às posturas e comportamentos dos pesquisadores, em face das opções que as distintas correntes temáticas oferecem.

No caso da geomorfologia fluvial stricto sensu, embora tenhamos diversas correntes temáticas de tratamento metodológico e algumas abordagens teóricas ortodoxas, não é possível encontrar uma concepção ou tratado teórico "fechado", único e totalmente delimitado com relação aos seus pressupostos teóricos, históricos e metodológicos. Nem mesmo uma obra de grande vulto teórico foi ainda concretizada. No que diz respeito ao estudo da evolução histórica que porventura possa haver entre os aspectos da hidrodinâmica, engenharia hidráulica, e, as próprias teorias geomorfológicas, é possível perceber, nitidamente, que pouca coisa foi pesquisada.

É com base neste contexto que este artigo tem como objetivo geral apontar a forte relação histórica entre geomorfologia fluvial, engenharia hidráulica e a hidrodinâmica, ou seja, de como o desenvolvimento de um campo científico incidiu na formulação de conceitos que responderam pela gênese histórica de outro. Para tal, foi realizada uma periodização da história desses três ramos das ciências naturais, evidenciando como os conceitos de ambos foram trabalhados de forma paralela e em diferentes óticas de abordagem. A conclusão a que chegamos é a de que a gênese da geomorfologia fluvial foi fortemente dependente das discussões que estavam sendo travadas na gênese da engenharia hidráulica e hidrodinâmica, isto é, de que o processo de constituição desse campo científico, conforme o método das aproximações sucessivas de Russel (1978) foi preponderante do ponto de vista epistemológico.

\section{Método de estudo e objetivos}

Para elaboração deste estudo foi tomado como método realizar a periodização histórica da geomorfologia fluvial, engenharia hidráulica e hidrodinâmica, analisando os conceitos e contexto histórico de cada época fundamentado no método das aproximações conceituais sucessivas de Russel (1978). Desta forma, foi possível visualizar os conceitos que passaram e/ou foram contextualizados de um período para o outro, sendo possível evidenciar a evolução dos conhecimentos vistos sobre as abordagens tanto geomorfológica quanto do ponto de vista da engenharia hidráulica e da hidrodinâmica.

Para tal foi selecionado uma linha de revisão bibliográfica de autores que tiveram suas pesquisas relacionadas a temas de engenharia hidráulica e geomorfologia fluvial, ou de outra forma, em autores que dedicaram de forma mais predominante à pesquisa do papel da água na esculturação da paisagem terrestre, seja em processos de canais abertos ou em sistemas de redes de drenagem.

A proposta de periodização apresentada foi fundamentada nos seguintes critérios:

- Primeiro, na leitura dos textos de importantes autores que trabalharam temas ligados aos processos fluviais e formação do relevo, e que ainda estão disponíveis para consulta;

- Segundo, na leitura de autores que discutiram de forma indireta determinados temas relativos às questões contemporâneas e históricas da geomorfologia fluvial.

Nossa variável mestre, portanto, é pela via de uma onipresente história geomorfológica fluvial. Doravante, nossa intenção é verificar como há pertinência de conceitos desta com a evolução dos conhecimentos pesquisados pela hidráulica fluvial e hidrodinâmica, as quais desde já salientamos, ofereceram amplo e profundo conhecimento para os primeiros trabalhos da ciência geomorfológica. De como houve ao longo da história omissão de determinados conhecimentos e entrelaçamento de outros. Neste sentido, esperamos estabelecer o perfil de desenvolvimento histórico-científico que consolidou a possibilidade da busca de uma base teórica, metodológica e de procedimentos técnicos que fundamentaram e direcionaram as pesquisas geomorfológicas fluviais. 
É sempre muito perigoso reduzir a história de uma ciência a um breve e pequeno esquema. Mas aqui a necessidade de simplificação se impõe com o objetivo de subsidiar o entendimento do início de um processo, seu complexo desenvolvimento e seu estágio atual de conhecimento. Portanto, ciente do contexto complexo de evolução histórica da geomorfologia, que tentaremos edificar, e, partindo de um viés da geomorfologia fluvial, propriamente dita, podemos construir uma proposta de periodização da seguinte forma. Em um primeiro momento, houve uma fase que podemos denominar de investigação dos processos hidráulicos e hidrodinâmicos em canais fluviais de escoamento aberto. Após, sem que haja necessariamente uma ruptura e transição nítida, um período que podemos considerar como o da classificação dos fatos morfológicos da paisagem, tendo como pano de fundo conceitos originados e aplicados a partir de uma embrionária ciência da morfologia fluvial. Em um terceiro período, o predomínio de um modo de fazer pesquisa com relativo abandono de campo e intensificação dos trabalhos experimentais, que iremos designar a época da experimentação e de estudo dos processos, e, por último, uma fase de volta aos trabalhos antigos, com uso intenso das técnicas modernas, que consideraremos como o período das integrações.

\section{Resultados e discussões}

3.1 A Investigação dos processos hidráulicos e hidrodinâmicos em canais fluviais (século XV a meados do XIX)

O primeiro período da história de estudo dos problemas ligados aos processos fluviais, não apresenta de maneira muito distinguível uma referência inicial que possibilita sua fundação ou a obra de um grande autor de referência. Aliás, isso pode ser considerado como uma característica trivial na história de quase todas as disciplinas científicas. Essa fase que ocorre aproximadamente do final do século XV até meados do século XIX, é marcada pelos estudos fluviais, hidráulicos e de hidrodinâmica que são realizados de maneira dispersa e pontuada em vários países da Europa, entre os quais, os dois mais importantes eram as escolas Italiana e Francesa de estudos hidráulicos (BISWAS, 1970), (ROUSE e INCE, 1957).

Já é um fato conhecido de todos que na idade média se tinha ampla curiosidade sobre a maneira como os rios se comportam nos canais naturais de escoamento aberto, e os "problemas" advindos dessa forma de es- coamento. Essa curiosidade pode ser notada nos escritos do engenheiro, artista e cientista Leonardo Da Vinci (1452-1519), que tem uma noção clara da origem da água dos rios, e dos trabalhos que eles podem realizar. Ele notava a poderosa ação que os mesmos causavam, quando desciam as montanhas dos Alpes e os vales que eram abertos pelo escoamento em canais de montanha. Da Vinci era arguto observador das relações que havia entre a variação da velocidade em canais fluviais e a distribuição e relação desta, com a largura e profundidade. Vale a pena sua citação extraída de Vieira da Silva et al. (2007, p. 19).

\begin{abstract}
$A$ velocidade da água é maior na superficie do que no fundo. Isto acontece porque a água na superficie está em acordo com o ar que oferece pouca resistência, porque é mais leve que a água, e a água no fundo esta em contato com a terra que tem maior resistência porque é mais pesada que a água e não se desloca. Disto se deduz que aquela parte que está mais distante do fundo tem menos resistência do que as partes inferiores (sic).
\end{abstract}

Portanto, nessa época já havia fortes especulações, sobre os fatores que interferem nas diferenciações dos fluxos que ocorrem encaixados nos canais, e, que são capazes de proporcionar diferentes níveis de resistência, e um embrionário conhecimento sobre o princípio da continuidade em seções fluviais. Iniciava-se deste modo e a partir desta época, os estudos sobre a hidrodinâmica.

De acordo com Orme (2002) a formulação inicial da mecânica como uma ciência física, estava presente nos trabalhos de Leonardo Da Vinci, sobre hidrodinâmica, Bernard Palissy (1510-1589) sobre ciclo hidrológico, Simon Stevin (1548-1620) na hidrostática, Benedetto Castelli (1577-1644) e Blaise Pascal (1623-1662) na mecânica dos fluídos. Essa fase, portanto, é fortemente marcada pela investigação e aplicação dos princípios originados no conhecimento das leis físicas da natureza - que operam de maneira cinemática as características dos fenômenos hidráulicos em canais de escoamento aberto na superfície.

Entretanto, coube a Domenico Guglielmini (16551710) a verdadeira edificação de uma nascente e integral ciência da hidráulica de rios, segundo as pesquisas de Morisawa (1985). Guglielmini era matemático, físico, 
hidráulico, médico e professor de hidrometria na Universidade de Bologna, Itália. Através de suas observações ele documenta a relação que há entre a inclinação e profundidade dos fluxos ao escoar e depositar no leito dos rios, expondo o conceito de equilíbrio de força e resistência na ação fluvial. Chega, dessa forma, ao tratamento da geometria dos canais e ao conhecimento do fato de que, a jusante, ocorre diminuição do tamanho das partículas dos materiais do leito fluvial. Fato que seria mais tarde confirmado pelas pesquisas experimentais de Leopold e Maddock. (1953).

Guglielmini através de seu Aquarum Fluentium Mensura Nova Methoda Inquisita de 1690 e do Della Natura dei Fiumi de 1697, pode ser colocado como o precursor direto da moderna geomorfologia fluvial, segundo Orme (2002), sendo um pesquisador que se posicionava, como forte defensor da linha de que em hidráulica, a observação é mais eficiente que a experimentação, e, que, consequentemente, o campo é melhor que o laboratório.

Morisawa (1985) também destaca que a hidráulica fluvial prática alcançou importantes avanços através de pesquisadores da escola Francesa, tais como Pierre Du Buat (1734-1809) e Antoine de Chèzy (1718-1798). A Du Buat se deve o conhecimento acerca da importância dos turbilhões e da velocidade no transporte de materiais nos leitos; sobre a resistência e formulação das equações de fluxo e a descrição das formas do leito. A Chèzy se deve a descoberta da primeira fórmula sobre o estudo que trata dos movimentos em canais, permitindo obter parâmetros de características de um canal, a partir de medições obtidas em outro. Os trabalhos desses dois importantes autores vieram a confirmar a teoria do fluxo uniforme que ocorre em um canal fluvial, quando as forças de resistência ao atrito da água, são iguais ou opostas às forças gravitacionais, provocando o movimento da mesma de montante a jusante, na superfície do leito. Portanto, nessa época também se chegava ao conhecimento da geometria da forma dos canais, aliada ao movimento dos processos e fluxos fluviais.

A passagem do século XVIII ao XIX e a continuidade deste, é marcada, sobretudo, pelo significativo avanço na teoria de transporte de sedimentos e em estudos feitos em laboratórios de hidráulica. Importantes contribuições vieram de Saint-Venant (1797-1888), Henri Émile Bazin (1829-1917) e Henry Darci (18031858), segundo Vieira da Silva et al. (2007), Vieira da Silva e Júnior (2005), Biswas (1970) e Rouse e Ince
(1957). O uso de modelos também floresce em pesquisas realizadas neste mesmo período; tais como os trabalhos de Louis Jérôme Fargue (1827-1910), que trabalha com modelos de leitos móveis, Osborne Reynolds (1842-1912), quem estudou os tipos de escoamento em condutos abertos e fechados, vindo a estabelecer um valor crítico para transição entre escoamento laminar e turbulento e William Froude (1810-1879) que desenvolveu técnicas para se testar modelos hidrológicos (MORISAWA, 1985).

No entanto, a despeito dos avanços que são feitos nos estudos de hidráulica e hidrodinâmica e das discussões sobre os processos fluviais concentrado em canais, é forte a influência científica, exercida pelo debate entre adeptos da teoria de formação da paisagem da terra pelos eventos do dilúvio, os diluviosos, designado também por catastrofistas e os pesquisadores que são influenciados pelas ideias originadas das teorias de James Hutton (1726-1797); um fazendeiro astuto e observador de processos erosivos na paisagem. Mesmo sabendo do poder de ação que os rios exerciam no desenvolvimento da paisagem, como já havia sido investigado pelos grandes autores da hidráulica fluvial, mesmo através da formulação dos conceitos e descoberta das constantes de importantes equações, acerca dos escoamentos em canais abertos, não houve concisa e sólida influência deste conhecimento nos debates que estavam ocorrendo sobre os fatos morfológicos da paisagem e origem da Terra, mais especificamente no campo da geologia. E essa discussão irá estimular a tomada de certas posições dogmáticas que não permitirá o entrelaçamento e a transposição dos conceitos das diferentes, mas "super-relacionadas" linhas de investigação e pesquisa, a morfologia fluvial (que mais tarde passa a ser denominada geomorfologia fluvial) e a hidráulica e hidrodinâmica fluvial.

Orme (2002), por exemplo, chama a atenção para o hiato temporal que existe na história geomorfológica; entre a confirmação da teoria de fluxo uniforme, da hidráulica, em meados do século XVIII, e a sua incorporação nos textos que tratam de assuntos de geomorfologia fluvial, sendo, primeiramente, tratada no livro de Leopold et al. (1964). Algo de aproximadamente duzentos anos. Hutton, que em seu Theory of the Earth de 1795, colocava novas questões sobre a formação do planeta, explorando uma variável de muita significância que age na essência dos fenômenos naturais, ou seja, a fluidez do tempo e sua importância, como chave de 
interpretação do passado - "o presente é a chave do passado" - e fundando o princípio do atualismo, fica praticamente canalizado no debate que há, entre os catastrofistas e os seguidores de suas ideias, mesmo que já houvesse avanços nas pesquisas sobre o poder erosivo dos canais levadas a efeito por engenheiros da hidráulica.

Dean (1989) levanta uma distinta e importantíssima questão ao dizer que pela indiferença que houve, com as ideias de Hutton, por parte de certos investigadores e pesquisadores britânicos, o leva a associar o efetivo fundamento da geomorfologia com o nome deste importante pesquisador. Fato que, certamente, dificultou o intercâmbio das ideias e conhecimentos dessas duas linhagens de investigação e pesquisa, ou seja, a morfologia fluvial e os estudos de hidráulica. É provável que Hutton, por ter sido fazendeiro e conhecedor da maneira de como se lidar com o solo, tivesse também, forte ciência da atuação de processos erosivos e da forma como a água se comporta na superfície da paisagem. Todavia, parece-nos que em suas ideias, não há ampla exploração do conhecimento advindo do estudo sistemático da hidráulica dos processos fluviais. Portanto, não há incorporação dos conhecimentos da hidráulica e aproximação e contato entre os diferentes autores, nos debates que se arrolavam sobre a origem da paisagem e da Terra.

Contudo, apesar de Hutton e dos nomes importantes que o seguiam, como James Hall (1761-1832) e John Playfair (1748-1819), este um dos mais combatentes adeptos de sua teoria, os catastrofistas vão influenciar fortemente os círculos do debate geológico, conduzidos pela forte atuação de Willian Buckland (1784-1856), importante representante das ideias catastrofistas, segundo Dean (1989). Questão que dificultou e aumentou a não aceitação da ideia dos processos agindo e mudando a superfície terrestre. Percebemos a prevalência de um forte ar de dogmatismo presente no debate. Tudo, provavelmente, começou a se modificar, cultural e cientificamente, quando Charles Lyell (1797-1875), em seu Principles of Geology de 1830, funda as bases e o conhecimento de uma ciência que reivindicava fortes argumentos, através da ação de forças internas, do poder solvente da água e advogava as forças dos processos fluviais para explicar a origem e os fatos da paisagem, de acordo com as importantes pesquisas históricas de Dean (1989). Esse fato será de suma importância no sentido de estimular contatos entre os pesquisadores de ambas diferentes linhas de tratamento, facilitando a emergência de novas abordagens e outros ângulos de visão dos mesmos problemas.

Já havia também, de acordo com Morisawa (1985), o início de importantes registros de pesquisas realizadas no Oeste da América, por ocasião dos avanços das frentes de ocupação dessa parte dos Estados Unidos, que levava a fundação segura de uma consciência sobre a ação dos processos fluviais e sua importância na formação da paisagem. Em particular os trabalhos de Newberry, Hayden e Dutton enfatizavam e documentavam a ação erosiva dos rios na formação de cânions e a imensidade dos processos fluviais. Surrel, em seu Études sur les torrentes des Hautes Alpes de 1841, já havia estabelecido as chamadas leis da morfologia fluvial e discorrido sobre a importância do nível de base geral para os processos erosivos atuais, segundo Abreu (1980).

Talvez, finalizando essa primeira parte de periodização histórica do estudo dos processos fluviais criador de uma fase iniciante de um importante debate que é marcado por uma transição sem ruptura, e, que foi o caminho condicionador do próximo período, devemos salientar os trabalhos de James Powell (1834-1902) e as pesquisas de Grove Karl Gilbert (1843-1918). A Powell se deve a designação formal e conceitual de um dos mais importantes princípios geomórficos, o conceito de nivel de base, segundo Chorley, Dunn e Beckinsale (1964). Deve-se a ele também, a primeira classificação genética dos rios, em consequente, antecedente e superimposto, segundo Morisawa (1985), que é utilizada ainda hoje. A Gilbert se deve a utilização dos conhecimentos da mecânica de fluxo dos processos fluviais, a definição dos conceitos de capacidade e competência fluvial, e, a concepção de interdependência de variáveis dentro do sistema fluvial (GILBERT, 1914). Suas investigações científicas são fortemente baseadas na sistemática observação, sendo esta, para ele, a primeira e mais importante etapa de uma pesquisa, salienta Rhoads e Thorn (1996).

Gilbert apresenta ser modernista em sua formulação e investigação, enfatizando os conceitos da mecânica e da quantificação, como demonstra o seu texto de 1914. Muitos dos conceitos desenvolvidos por ele foram adaptados e integrados por Davis $(1902,1938)$, nos textos em que este faz uso compreensivo dos fatos da geomorfologia fluvial, para expor suas ideias de ciclo geográfico. Suas pesquisas são fundamentais como o marco de um processo de transição, com assimilação 
e incorporação de conceitos trabalhados nas pesquisas de hidráulica, produzidas em anos posteriores, e, consequentemente, contextualizado para o campo dos estudos morfológicos. Sua formação em física, engenharia hidráulica e geologia, facilitava essa interdisciplinaridade.

Portanto, essa fase vai ser marcada pelo debate de temas inter-relacionados, mas que ocorrem em discussões compartimentadas, marcada por barreiras dogmáticas, problemas de linguagem e formação acadêmica. Se de um lado há geólogos preocupados com a investigação da Terra, inferindo sobre eventos e buscando as evidências que os representam; de outro, há pesquisadores ligados a uma formação física e matemática, relacionada à engenharia hidráulica e tentativa de entendimento de processos hidráulicos com base na dinâmica e mecânica dos fluídos. Já se evidência nesta época problemas sérios relacionados à formação básica dos pesquisadores, que tanto nos assola nas pesquisas em geomorfologia do período atual. Os temas, de certa forma, se inter-relacionam, mas devido aos diferentes ângulos de visão de um mesmo problema, não há muita interdisciplinaridade. E há pesquisadores como Powell e Gilbert, que a despeito de uma formação acadêmica profunda, mas, sobretudo ampla, conseguem desenvolver extensos e abrangentes trabalhos de pesquisa, fazendo uso de conceitos de diferentes áreas.

Esta fase pode ser considerada como a tentativa, ainda que sem o testemunho de fortes elementos, da compreensão de determinados fatos da morfologia fluvial - tais como o poder erosivo dos rios por exemplo - por meio das características da paisagem; em uma procura de entendimento dos processos fluviais, tomando como base os aspectos morfológicos da paisagem. É dessa forma que o próprio Leonardo Da Vinci, grande cientista citado anteriormente, irá dizer, "cada vale foi escavado pelo seu rio, e a relação entre os vales é a mesma que entre os rios", (DA VINCI apud CHRISTOFOLLETI, 1970, p. 05). Playfair, importante seguidor de Hutton, também irá declarar,

“... cada rio consiste em um tronco principal, alimentado por um certo número de tributários, sendo que cada um deles corre em um vale proporcional ao seu tamanho, e o conjunto forma um sistema de vales comunicantes com declividade tão perfeitamente ajustadas, que nenhum deles se une ao vale principal em um nivel demasiado superior ou inferior: circunstancia que seria infinitamente improvável se cada vale não fosse obra do rio que o ocupa", (PLAYFAIR, 1802 apud CHRISTOFOLLETI, 1970, p. 05).

Portanto, esse vasto período, é depositário do início de um importante processo de busca da compreensão dos mecanismos relacionados às formas de manifestação fluvial da superfície, por meio da morfologia da paisagem e a responsabilidade em sua evolução.

\subsection{A classificação dos fatos da paisagem e os processos fluviais (início do século XX à 1945)}

Se o período anterior pode ser tomado como o da tentativa de compreensão dos processos fluviais, usando a morfologia dos terrenos como instância de análise, o posterior deve ser empreendido como o do entendimento da origem e fisionomia morfológica do modelado, através dos processos fluviais. O problema, portanto, se desenrola no sentido um tanto inverso. É dessa forma que Davis $(1899,1902,1938)$, fazendo uso do conhecimento que já se tinha do poder dos agentes fluviais procurará consolidar os argumentos e bases que fundamentam toda a sua proposta teórica do ciclo geográfico, aplicado ao desejo de explicar a gênese das paisagens continentais.

Penck (1953), por sua vez, também não abrirá mão da ação fluvial para explicar a evolução das vertentes em seu sistema teórico de explicação e, King $(1953,1956)$ que foi um crítico contumaz de Davis, embora grande admirador pessoal, também fará uso de mecanismos hidráulicos, sobretudo, no que diz respeito às críticas que ele faz a proposta Davisiana com relação ao tema da evolução das vertentes e os processos de pedimentação.

Nessa época, uma ciência própria do relevo já se encontra em estágio final de consolidação, com um corpo de ideias e cientistas apresentando posturas consistentes, embora o termo geomorfologia surgisse alguns anos mais tarde. Havia também a realização de reuniões para discussões de temas relativos à paisagem. Esta fase histórica tem início a partir das discussões, sobre as ideias de Davis, no começo do século XX até as publicações de Horton em 1945, no final da Segunda Guerra Mundial. Todavia, os textos de King que são publicados na década de 1950, devem ser colocados 
como representativos das características desse período da história geomorfológica. Uma característica forte dessa época é o forte debate e agrupamento das discussões em torno das indagações oriundas do estímulo, a curiosidade sobre as questões geológicas como a origem dos continentes, das montanhas, dos grandes cinturões vulcânicos e dos mares e oceanos.

Outros importantes autores também são representativos dessa fase da geomorfologia fluvial, no entanto, concebemos esses três principais pelo fato de suas propostas terem alcançado maior notoriedade nos círculos de discussão geomorfológica. Nestes textos escolhidos é possível encontrar fortes meditações em torno da importância de um raciocínio, a partir de variáveis fluviais, para se meditar sobre a natureza do ambiente geomórfico. A estes três pesquisadores, creditamos a existência de um tratado teórico que se complementa em termos de argumentação lógica e aproximações conceituais sucessivas (RUSSEL, 1978). Questão que já foi muito bem tratada por Abreu (1982), embora não concordemos com ele em certos aspectos. É de suma importância tecer alguns comentários, ainda que de maneira rápida, sobre os textos de Davis (1938), Penck (1953) e King (1953), que desde já salientamos serem os mais significativos e importantes da aplicação dos conceitos, originados no campo de estudo dos processos fluviais para entendimento - e agora já é viável falar - da análise direta da origem e evolução das formas de relevo.

O texto de Davis (1938) é o último de sua prestigiosa carreira como pesquisador e professor na universidade de Harvard. Basicamente, ele trata da evolução das formas de relevo em regiões desérticas, tendo como área de estudo, o deserto de Mohave no sudeste da Califórnia. Ele discorre, precisamente, sobre os processos fluviais que são responsáveis pela evolução das formas em áreas áridas desérticas, a qual denominou de sheetfloods e streamfloods. Portanto, ele trata não só de morfologia das feições, mas, tenta, sobretudo, aplicar conhecimentos de processos.

Segundo Davis, sheetfloods são processos que ocorrem em ambientes desérticos quando em um determinado período, durante eventos de tempestades com chuvas rápidas, torrenciais e intensas, se forma um gigantesco emaranhado de fluxos e inundações em lençol que escoam pelas vertentes montanhosas, lavando os depósitos detríticos, compostos de areias, materiais pedregosos e cascalhos que são oriundos do intemperismo, predominantemente físico, sobre rochas graníticas fraturadas e exumando as demais estruturas rochosas. Os streamfloods, por sua vez, também se formam nos mesmos ambientes, sendo os processos pelo qual, em um momento de ativada a erosão pelos escoamentos de inundação e em lençol dos sheetfloods, redes de fluxos se canalizam, organizando-se em pequenas confluências, escavando sistemas de vales fechados, ao longo das vertentes que estão distribuídas paralelamente às montanhas. Devem ser chamados de streamfloods, ao invés de simplesmente stream, porque o caráter de fluxos espasmódicos, irregulares, não totalmente perene, se conserva, não caracterizando a drenagem peculiar das regiões úmidas.

Esse texto de Davis, fundamentalmente, é dividido em quatro partes, onde na primeira é discutida a ação dos sheetfloods, sobre as vertentes detríticas das superfícies planas agradacionais desérticas; a segunda, trata das condições nas quais os sheetfloods são transformados em inbranching streamfloods, voltando, após um processo cíclico natural de rebaixamento de superfícies inter-divisoras, a serem sheetfloods. A terceira parte discute o papel desses processos no desenvolvimento do ciclo de erosão em regiões desérticas e a quarta trata das condições regionais em que há degradação dos níveis de base e da sua importância como controladores desses processos erosivos. Chama a atenção o uso do termo "fisiográfico", em substituição ao "geográfico". Fato que atesta uma insuspeitada mudança de postura conceitual nessa fase de sua obra.

Poderíamos fazer amplos comentários sobre este belo trabalho, todavia, não é preciso ir muito longe no sentido de se perceber o amplo uso dos conhecimentos fluviais, na defesa de suas ideias que continuam solidificadas uma vez que, a esta altura do debate, Davis estava sendo amplamente bombardeado, por críticas aos seus trabalhos. Daí se visualiza uma provável mudança de postura com relação a certos temas, como por exemplo, o da aceitação do papel da erosão no processo de recuo lateral das vertentes em áreas desérticas, embora ele chegue à conclusão no final do texto, de que tem pouca ou nenhuma importância esse sistema de evolução. A utilização do conceito de rios intersequentes e sua importância para evolução dos vales, extraído dos trabalhos de Buwalda (1932), e, a aplicação dos conhecimentos de hidrologia no entendimento dos eventos de inundação e escoamento em lençol nas áreas de formação de pedimentos, certamente, tomados de Bryan (1922), estão explicitamente presentes em sua análise. 
A operacionalidade de suas explicações, com relação ao desenvolvimento da drenagem intermitente e canalizada dos ambientes desérticos, controladas pelo conceito de nível de base, seja regional ou geral, também é aplicada para compreender e explicar processos de denudação. Este texto, também quebra a opinião, às vezes pregada erroneamente por professores de geomorfologia, de que Davis não trabalha com o conhecimento dos processos em sua dinâmica para entender os mecanismos de evolução da paisagem.

Não estamos solicitando a tese de que sem os conhecimentos da geomorfologia fluvial, Davis não teria adquirido grande projeção teórica. E, nem de que não teria chegado a significativos avanços nas suas explicações sobre a evolução cíclica do relevo, fato, que de todo modo, é de natureza muito óbvia. Entretanto, é importante frisar a superação e a mudança de postura, adquiridos a partir do conhecimento da leitura de certos autores que aparecem em sua bibliografia, e a lisura de suas explicações, quando leva em consideração a aplicação de conceitos originados das discussões sobre temas da morfologia fluvial em uma época anterior. A identificação de processos, tanto do passado, quanto do presente, também é de grande valia neste texto. Contudo, Davis não abre mão de sua marca principal, o do entendimento da evolução fisiográfica da paisagem, a partir da classificação de suas feições morfológicas, ou seja, da disposição geométrica das formas da superfície no espaço em conexão com o tempo.

Se Davis apresenta uma quantidade maior de textos publicados, e que ainda é possível ter acesso, Walter Penck, embora publicasse menos, possui uma produção mais densa, de leitura mais difícil e onerosa, no entanto, desafiadora. Seu livro Die Morphologische Analyse. Ein Kapital der physikalis - chen Geologie, publicado em 1924, traduzido e publicado em inglês em 1953, com o título "Morphological Analysis of Land Forms - A contribution to physical geology" é uma obra densa, onde, fazendo uso dos conhecimentos da morfologia - concebido como o estudo do relevo da terra - tenta explicar problemas ligados aos movimentos crustais da superfície, considerado por ele, como de assunto exclusivo da geologia física, daí o subtítulo do livro.

Seu livro possui um complexo jogo de raciocínio sobre as questões ligadas aos processos responsáveis pela evolução das formas da superfície. Todavia, não é de seu desejo tratar explicitamente de evolução da superfície. Sua principal intenção é procurar compreender e explicar os problemas relacionados aos movimentos da crosta terrestre. E é a partir dessa noção de convergência que ele vai propor uma análise baseada em três elementos: os processos exógenos, processos endógenos e os produtos da relação entre ambos, que é designado pelas feições morfológicas atuais. Esse terceiro elemento é derivado de um jogo de equilíbrio de forças que há entre agentes exógenos e endógenos. A aplicação da relação entre depósitos correlativos chamados de correlated strata, para análise e recuperação da história deposicional, e, assim inferir o desenvolvimento de áreas associadas de denudação, também é ponto marcante neste texto.

Talvez uma das fortes características de Penck, assim como Davis e King, seja a eficiência e a persistência do método, advindo de longos trabalhos de campo. Fato que, curiosamente, marca esse período da história de produção intelectual morfológica, onde o modo de se fazer pesquisa era em contato direto com o objeto, a análise minuciosa e a busca de dados na fonte. Eram desse modo, grandes pesquisadores de campo.

Isto cristaliza e fundamenta a ideia de classificação dos fatos morfológicos, atributo intrínseco deste período e modo de fazer ciência, pois o contato com a natureza, a objetividade da observação, a perspicácia e insistência da curiosidade - estimulada no contato direto com a paisagem - solidifica e contextualiza o desejo de entendimento, através de parâmetros descritivos e/ou níveis de classificação das formas observadas. A construção teórica é feita a partir da observação/descrição indo para a classificação. Às vezes, a partir da descrição eram capazes de ir direto para a teoria, sem necessariamente ter que perder tempo com etapas de análise e interpretação. Uma importante citação de Penck (1953, p. 04), nos faz perceber este fato, quando escreve,

All the processes of denudation have, as gravitational streams, a no-uniform character-which, as will be shown, is in contrast to the processes of reduction. That is their fundamental property. Their commencement, their course of development, take place before our eyes. They can be observed in all their phases, and their systematic investigation is thus possible everywhere on the earth, not only qualitatively - as has already been more or less fully done - but quantitatively, a matter which so far has been hardly attempted 
Esse estilo de produzir ciência somente é construído à custa de grandes viagens e trabalhos de campo. Isso irá permitir que Penck viesse fazer amplas comparações e correlações sobre as feições observadas, facilitando a descoberta da essência de fenômenos e atributos de processos que respondem pela natureza das formas. Chama-nos a atenção, já que estamos analisando a história da geomorfologia pela via de uma história de seu ramo particular, a geomorfologia fluvial, o modo e linha de raciocínio, ao aplicar os conceitos de nível de base de erosão e nivel de base de denudação. Certamente, uma evidência elementar da leitura profunda dos textos de Powell, que sem sombra de dúvida, o auxiliou nessa argumentação.

Para Penck, o nivel de base de erosão é o limite de rebaixamento absoluto a partir do qual o movimento da água não seria capaz de remover nenhum material. Não é uma superfície, não é um ponto, não é uma forma visível, é, portanto, um nível, podendo ser o mar ou qualquer depressão rebaixada, no interior dos continentes. Pode ser chamado também de nivel de base absoluto de erosão. Esse nivel de base de erosão poderia ter implicações locais, podendo ser compreendido a partir de outro, que é denominado como nível de base local de erosão, que se divide em dois grupos. O primeiro seria o de pequenos cursos de água que drenam vastas áreas, onde uma mudança de nível só seria possível no sentido vertical, rebaixando esse nível, quando há erosão da calha ou soerguendo, quando ocorre deposição de sedimentos. O segundo seria encontrado nas extensões fluviais dos leitos dos rios, nos lugares em que há pausas no gradiente do leito. Assim, teríamos diferentes níveis, separados por seções que controlam as taxas de erosão, associados com mudanças fundamentais na intensidade da ação fluvial.

$\mathrm{O}$ nivel de base de denudação é o conjunto de pontos da superfície, aonde não é permitido rebaixar ou desenvolver as vertentes das formas. Seria cada ponto da vertente que controla sua denudação dada por zonas de resistência rochosa ou diferenciações litológicas. Assim sendo, o número infinito de níveis de denudação distribuídos na superfície, formaria o nível de base geral de denudação, que poderia coincidir com o conjunto das seções de pausa das calhas dos rios perenes e intermitentes, os quais não seria possível rebaixar os gradientes da superfície. Tal nível pode ser comparado aos sistemas de curvas idênticas às curvas gradientes dos cursos d'água.

Penck (op. cit. p. 126-127) alerta sobre a impli- cação "hidráulica" e "hidrogeomórfica" que há nestas seções quando escreve,

These levels separate sections with a steeper gradient from those above or below which possess a gentler slope. Associated with them is a fundamental change in the intensity of river action. They are not fixed in position, but migrate upstream; (...).

Pensamos o quanto é importante a operacionalização destes conceitos nas pesquisas de geomorfologia fluvial, acoplado aos estudos estruturais. A descoberta desta essencial aplicação conceitual, por si só justifica toda a periodização histórica da construção dos conceitos geomorfológicos. Deve ser sempre estímulo aos estudantes na busca histórica do conceito, a resgatá-lo, em fazer a recuperação e a transposição de sua memória, à luz das técnicas modernas de pesquisa e em diferentes ângulos de abordagem. Eis a essência implícita de uma pesquisa científica.

Com esta linha de raciocínio Penck foi capaz de perceber que o nível de base geral de denudação, não depende diretamente do nível de base geral de erosão, uma vez que o primeiro é controlado pelas pausas dos gradientes das calhas fluviais que se localizam de maneira pontuada, ao longo dos perfis longitudinais dos leitos fluviais que compõem a rede que drena a superfície. Deste modo escreve,

It is not everywhere, however, that the base
levels of denudation coincide with those of
erosion and the erosional tracks. Their inde-
pendence of the latter becomes evident, for
instance at those very many places in arid
regions where mass-movement, even in its
last outlying portions, does not reach as far
as the lines of the intermittent streams. This
same lack of dependece, which demonstrates
the functional independence of the base levels
of denudation, is especially clearly visible in
scarplands (PENCK, $p$. 128).

É a partir desta constatação que ele conseguirá entender e explicar a heterogeneidade de diferentes estágios de evolução das vertentes viajando pela Cor- 
dilheira dos Andes na Argentina. Em qualquer bacia fluvial é possível fazer comparações destas relações entre estágios distintos de evolução de vertentes, controladas pelas posições, tanto horizontais quanto altitudinais, dos níveis de base de denudação e de erosão. É evidente que, em tal empreendimento, deve-se tomar como unidade de referência a bacia de drenagem em toda a sua configuração territorial, na relação com os diversos níveis desnudados da superfície.

O seu tratado teórico é fortemente fundado sobre um profundo conhecimento que o mesmo tem da ascensão e subsidência de blocos que compõe a crosta e os processos atmosféricos que atacam e arrasam o modelado terrestre, sustentado por esses blocos. Assim, sua visão é baseada, acima de tudo, em uma concepção físico-química que ele tem da natureza dos processos geomórficos. Seu sistema é, portanto, um sistema físico, químico, e, porque não, associado a uma base de visão da mecânica da natureza. Contudo, sobre uma base teórica totalmente explícita e de cunho mais interdisciplinar que a teoria de Davis.

Por fim temos Lester C. King (1953), geólogo e geomorfólogo da África do Sul, que trabalhou no Brasil e em territórios da África, comparando vastas superfícies de aplainamento destas duas regiões. Além de fazer profundo uso de seu método, era um grande pesquisador de campo.

$\mathrm{O}$ grande interesse de King em um de seus poucos textos em que ele trata, exclusivamente, de questões teóricas, é fundar os princípios gerais que permite entender e explicar a evolução da paisagem, vista através de outro ângulo. Para tal, rejeita totalmente o conceito Davisiano de rebaixamento gradual das vertentes como processo geral de desenvolvimento da paisagem, bem como o seu peneplain. Discorre sobre essa evolução, tendo como alicerce, a ideia de recuo paralelo das vertentes com a formação consequente dos pedimentos - setores de superfícies planas em formato ligeiramente côncavo, dispostos na base das escarpas que ao se coalescerem dariam origem às grandes paisagens pediplanadas. O pediplano, segundo ele, é o produto final da junção dos pedimentos.

No entanto, o que podemos examinar, em termos de aplicação dos conhecimentos de processos fluviais, é a forma na qual King faz uso destes atributos para tentar chegar a uma visualização dos princípios gerais que regem a evolução modelar da superfície. Com certeza, foi dos três autores, aquele quem mais aplicou os informes de uma assídua disciplina da hidráulica e morfologia fluvial para explicitar o poder das suas ideias.

King tinha uma clara concepção de que trabalhando a gênese e a formação dos pedimentos, chegaria ao entendimento geral da origem das principais feições geomórficas da paisagem, onde ele dizia,

No matter how, or by what agencies, a pediment is later modified; its very existence depends in the first instance upon the process of hillslope or scarp retreat. Thus any hypothesis of pediment formation must explain not only the form and remodelling of the pediment but also the reasons for parallel retreat of hillsides and scarps (King, 1953, p. 732).

Para tal, salientava que as bases de seus argumentos assentavam na forma em que a água fluía, derivada da chuva sobre a paisagem e de observações pontuais e exames feitos no campo, em momentos de precipitação e do processo em operação. Isso implica trabalhar em um nível de conhecimento profundamente assentado em bases hidrodinâmicas. Em ter ampla habilidade intuitiva para se apreender todas as circunstâncias responsáveis pela variação dos processos geomórficos, condicionados pelo fluxo da água ao escoar pela superfície dos terrenos. Não houve como, fazendo uma leitura de seu método científico-investigativo, dele prescindir dos conhecimentos da hidrodinâmica.

Para King, o pedimento pode ser considerado como a forma de "relevo ideal", resultante da relação entre a água projetada sobre a superfície pela precipitação, em muitos casos de caráter torrencial, e o modo como se processam os mecanismos que são responsáveis em elaborar o mínimo de transformação pelos processos erosivos advindos dessa projeção. É tomando este contexto que ele percebe,

The pediment, a smooth landform permitting discharge in sheets over its whole area, is indeed the natural answer to the need for rapid dispersal of storm water: it is the ideal landform to dispose of the maximum volume of water in minimum time, with least erosional damage to the landscape. Pediments, once formed, may thus be expected to be relatively stable landscape features (King, 1953, p. 733). 
Neste sentido, seguirá uma linha de raciocínio fortemente assentada sobre as bases da hidráulica de fluxos em superfície, almejando explicar os mecanismos que regem a dispersão da água sobre os terrenos planos, respondendo pela gênese das principais feições componentes dos pedimentos. Em cada feição componente dessas formas, há um comportamento diferente dos fluxos, em que a forma é o resultado do processo atuante sobre ela, ao passo que a própria forma, também é condicionadora da natureza do processo, neste caso, processos hidropluviais e hidrogeomórficos.

King particularmente negava, como acredita certos autores, que os pedimentos fossem resultante de ações fluviais de migração lateral dos rios perenes e efềmeros, assim como discordava fortemente de Davis, com relação à evolução das encostas por rebaixamento dos topos e diminuição dos seus ângulos de inclinação. Suas declarações sempre defendiam a origem dessas feições, através da consideração de um recuo paralelo das escarpas, morros e vertentes, acompanhados de relativa estabilidade em alguns casos, dos ângulos de inclinação.

Sua sensibilidade era acompanhada de uma vigorosa confiança nas virtudes da observação, onde equipado com os conhecimentos originados da visualização de processos in situ, localizados nas mais diferentes regiões do mundo, era-lhe permitido fazer criteriosos exames de investigação, aplicando conceitos adquiridos de leituras específicas, mas que eram contextualizados para o campo da proeminência geomorfológica.

É por meio deste contexto que, tomando o conhecimento da hidráulica de fluxos superficiais, consegue fazer uma análise das características desses processos, chegando a partir de uma aplicação do conceito de Osborne Reynolds sobre escoamento laminar, turbulento e o valor crítico de mudança de estado do escoamento, a apreciação e descoberta dos agentes e mecanismos que respondem pela modelação e remodelação dos pedimentos. É através dos atributos da observação que a ele era concedido adquirir informações sistemáticas sobre os fatores responsáveis pela evolução atual dos pedimentos, e, assim declarar,

Across the pediment, where the volume of water to be discharged continues to increase, the sheet of flowing water becomes deeper. Commonly it also becomes turbid and erosive again. Reynold's Number once more affords the explanation for, when the sheet of water passes a certain critical thickness defined chiefly by the viscosity of water and the smoothnes or ireegularity of the ground, the sheets of molecules break up, and linear flow takes place again. This sheet-flood (as distinct from the laminar flow in sheets) is the agent that erodes and models the pediment into its typical hydraulic cross section. In addition to transporting weathered debris, its is an active eroding agent on its own account (KING. 1953, p. 734).

E ele vai mais longe, ao argumentar que em certas circunstâncias há a concentração de fluxos lineares que resultam na produção canalizada de redes fluviais sobre a superfície dos pedimentos, com formação de cabeceiras em recuo remontante e atravessando a sua largura total, re-afeiçoando e remodelando-os. Assim sendo, era-lhe possível inferir os processos que são responsáveis pela formação dos variados tipos de pedimentos e geometria de seus elementos componentes, tais como a free face, waxing slope, debris slope, waning slope, talus, e soil.

Não é preciso discorrer inteiramente sobre esse trabalho de King (op. cit.) para sentir o quanto foi importante o desenvolvimento prévio de uma "ciência do comportamento da água", sobre a geometria do modelado, como mediadora e auxiliadora da resolução de conflituosas questões geomorfológicas, até então, amplamente debatidas nesta época. Nem é necessário entrar de maneira detalhada, no mérito da questão argumentativa de King, sobre os fatores gerais de evolução da paisagem que foram discutidas também por ele no final do texto. Circunstância que, de todo modo, não é de nossa intenção. Contudo, nosso desejo é demonstrar a importância que o mesmo prescreve, ao considerar as questões ligadas aos processos fluviais; seja em escoamento concentrado, reafeiçoando as formas componentes dos pedimentos, ou em lençol, edificando a geometria regular plana que caracteriza essas feições da paisagem. Com isso, ele chegou pari passu a plausíveis resultados sobre as propriedades e dinâmica dos processos, configuradores de uma gênese pedimentar.

Portanto, esse momento da história geomorfológica representa uma época de consideração indireta das questões de hidráulica e morfologia fluvial, no 
sentido de uma aplicação para entendimento e elaboração de teorias que procurassem resolver, de maneira geral, as indagações geomórficas, tendo como pilares principais, a abordagem histórica das formas de relevo e uma cronologia relativa de denudação. E, estes três autores são muito representativos dessa forma de fazer ciência, tomando como base a observação, munidos de forte preparo intelectual para classificação conceitual de fenômenos geomorfológicos, tendo como método a investigação direta do objeto, em trabalhos de campo. Observação - reflexão - sistematização - classificação e teorização são etapas fundamentais encontradas e que condicionavam a produção científico-geormofológica nesta época. No entanto, para finalizar este período, devemos frisar que eles não foram totais idealizadores dos conceitos que utilizaram para formular suas concepções teóricas. Por exemplo: a importância do conceito de nível de base na investigação dos processos fluviais, já estava sendo trabalhada por Surell, por volta de 1841, conforme Abreu (1980), sendo que sua definição geral e formulação conceitual formal aparecem em Powell, em um trabalho de 1875, sobre o rio Colorado no oeste de New York, (Chorley, Dunn, Beckinsale, 1964). Portanto, há uma forte inter-relação entre a sequência de trabalhos realizados, com aperfeiçoamento de conceitos, e, introdução de novos ângulos de abordagem sobre os problemas pesquisados que tende a levar a uma aproximação mais condizente com a realidade do objeto investigado.

\subsection{A época da experimentação e de estudo dos processos}

Se o período anterior é munido de forte projeção investigativa a partir de um tratamento que podemos considerar por meio de uma teoria "fechada", explicitamente rica em reflexão, observação e aplicação de método, o posterior se desvanece em uma prática científica assentada em incipientes sistemas de teorização, com abandono relativo dos vultosos trabalhos de campo e com uma fraca reflexão empírica. Entretanto, configura-se como uma ocasião de conjuntura fortemente fundamentada na experimentação, nos ensaios de medição, no monitoramento de parâmetros matemáticos e na forte valorização de uma "natureza" transferida e investigada em laboratórios, para verificação, na grande maioria das vezes, de eventos e processos hegemonicamente fluviais.
Esta fase pode ser tomada, por uma referência inicial, a partir da Segunda Guerra Mundial, através das publicações do engenheiro hidráulico Robert Horton (1945), se estendendo pelos anos da década de 1950, 1960 e 1970, sendo seu período final, algo meio confuso, em uma transição para a fase histórica posterior, no entanto, com propriedades que nos possibilita traçar considerações sobre diferenças de abordagem científico-geomórfica, entre essas duas épocas. Trabalhos clássicos surgem nesta época como os de Strahler (1952), Schumm (1956), Leopold et al. (1964) e outros.

A época de estudo dos processos é um momento marcante na história da geomorfologia, sobretudo nos estudos de processos fluviais, por que define uma mudança de conduta e de produção científica, onde o enfoque investigativo sinaliza uma transformação de paradigma. E, aqui, podemos até citar Khum (1998). Há de certa forma mudança de paradigma no campo geomorfológico fluvial, e por consequência, na própria geomorfologia. Deixa-se uma análise fundamentada no estudo da história geomórfica da paisagem em favor de trabalhos centrados nos estudos dos processos. Quiçá, abrem-se mão das análises puramente teóricas, de elementos de conotação histórico-geológica, pelo aprofundamento da experimentação, da precisão da observação, pelo refinamento dos dados e informações derivadas de instrumentos técnicos de monitoramento, equipamentos de laboratório e modelos que tentam, em escala reduzida, imitar os vetores da natureza - por meio de variáveis de equações matemáticas - responsáveis pela dinâmica dos ambientes e processos fluviais.

Não há nesse momento, o surgimento de um individual, total e inédito sistema de concepção teórica. Nem um autor que se defina por uma só linha metodológica. A geomorfologia fluvial, praticamente se funde com as técnicas hidrológicas e hidráulicas, bem como com outros métodos da estatística. Anteriormente, utilizava-se de conceitos da hidráulica experimental de processos para subsidiar a análise de problemas geomórficos, agora a análise geomórfica é uma aplicação imediata de conceitos e técnicas que são trabalhados a partir da contextualização de termos buscados, no campo científico dessas disciplinas e outras correlatas, entre as principais, estão a Física, a Química, a Mecânica e a Matemática. Trata-se de uma consequência da evolução do progresso técnico no pós-Segunda Guerra, tendo impacto direto em todos os campos disciplinares científicos. 
Se na abordagem histórica do período anterior, valorizavam-se em trabalhos de campo, as feições e processos que poderiam exercer o papel de herança dos ambientes pretéritos, para análise das evidências processuais auxiliares na interpretação do meio geomórfico, agora, procura-se mensurá-los no momento exato de sua ocorrência, ou através de modelos de experimentação laboratorial. Não que nessa época também não houvesse a busca de entendimento da história de evolução da paisagem, ela não é totalmente abandonada; todavia, é posicionada em plano secundário na análise, sendo solicitada somente com o objetivo de subsidiar o entendimento das características contemporâneas dos processos. Uma breve compilação dos principais trabalhos publicados nessa época demonstra as características da esfera de discussão científica, dado por meio de uma sequência de publicações que consideramos como mais representativas. Quase todos os trabalhos possuem relação com temáticas ligadas à geomorfologia fluvial.

O primeiro, e, que pode ser apreendido como ponto de ruptura é o trabalho de Horton (1945), que utiliza os princípios das leis hidrofísicas para examinar como a infiltração, o escoamento superficial e as características das vertentes, se combinam para dar origem aos canais fluviais e ordenar as redes de drenagem, dentro de uma análise puramente estatística. Horton é considerado, devido aos trabalhos anteriores que vinha realizando, o idealizador da análise sistemática e estatística dos parâmetros hidrográficos das bacias de drenagem.

Posteriormente, aparece Strahler (1952), com seu intento de fundar as bases da dinâmica aplicada ao campo de estudo dos processos geomórficos, que para Ritter (1988), Rhoads (2006) e Orme (2002), marca o ponto de mudança de paradigma, dentro da ciência geomorfológica. Questão a qual, evidentemente, não concordamos.

No modelo dinâmico de Strahler os processos são análogos às tensões que agem, sobre os diferentes materiais geológicos, produzindo características variáveis de tensão e falhamento. As falhas manifestam respostas diferentes de tensão e expressam a mecânica do intemperismo, erosão, transporte e deposição, em acomodações entre tensão e deformação dos materiais que são heterogêneos em sua composição. Tal abordagem dinâmica requer que os processos sejam analisados, em termos de sistemas abertos, a qual tende alcançar uma condição estável e se auto-regular. Esses sistemas e processos mecânicos podem ser expressos em modelos matemáticos, derivados da análise empírica e racional de dados observados. Strahler sugere, nada mais, nada menos, a ideia na qual o processo geomórfico pode ser tratado como um fenômeno stress-strain operando em sistemas abertos. Tal abordagem foi de grande valia para a geomorfologia de processos fluviais e hidrologia de vertentes.

Após Strahler, aparecem Leopold e Maddock (1953), em interessante trabalho publicado no Geological Survey Professional Paper, do Serviço Geológico Americano, no ano de 1953, onde é pesquisada a relação entre geometria hidráulica de canais fluviais e algumas de suas implicações fisiográficas. Estes autores apresentam, por meio do estudo da geometria hidráulica de vários canais fluviais de escoamento aberto, o contexto pelo qual os sistemas fluviais desses canais tendem ao equilíbrio manifestado pelo ajuste das variáveis hidráulicas dos rios. Há, segundo eles, uma tendência nos ambientes de sistemas de canais ao desenvolvimento de uma forma de equilíbrio aproximado entre o canal, a descarga e os sedimentos que o próprio canal é capaz de transportar e depositar. Com isso, a geometria hidráulica, como uma das vertentes de pesquisa da geomorfologia fluvial, estava praticamente fundada.

Em seguida vem Schum (1960), Schum e Khan (1972) e Schum (1981), onde são apresentados os resultados de uma série de estudos experimentais realizados em complexos laboratórios de monitoramento e de modelos de escala reduzida, objetivando investigar a relação que há entre variações de padrões de canais e tipos de cargas transportadas. Valores limiares são encontrados, demonstrando às funções que as variáveis exercem, dentro da dinâmica do ambiente fluvial, inclusive a influência que o tempo exerce sobre tais, e o sistema como um todo. Em Schum (1981), são apresentadas as implicações sedimentológicas, evolução e resposta do sistema fluvial às alterações nos valores desses limiares e os tipos de configuração do padrão de canal fluvial, condicionados por períodos de transição, estabilidade e mudança total de padrão geométrico, ocasionados por transformações nos fatores ambientais responsáveis pela natureza desses limiares do sistema.

Outros importantes trabalhos também são muito representativos dessa fase, como Leopold e Miller (1956), Wolman e Leopold (1957), Leopold e Wolman (1957), Strahler (1958), Bagnold (1960), Wolman e Brush Júnior (1960), Leopold et al. (1960), Brush Jr. (1961), Brice (1961, 1973), Schum (1961), Leopold e 
Langbein (1962), Leopold, Wolman e Miller (1964), Smart (1973), Hack (1973a, 1973b), Keller e Melhorn (1973), Yang e Stall (1973), Hickin (1973), Tricart (1966) e outros. No Brasil, os autores mais representativos e fortemente influenciados por esses trabalhos foram Christofoletti (1970, 1981), França (1968) e Gandolfi (1968).

Embora todos esses trabalhos listados não fossem alicerçados em teorias explícitas, eles auxiliaram a compreensão mais detalhada de questões mal resolvidas nas fases históricas anteriores, como o problema da natureza e dinâmica dos meandros, das tipologias e transformações geométricas dos canais, da hidráulica de canais de escoamento concentrado e aberto, das planícies de inundações, as implicações sedimentológicas de bacias afetadas tectonicamente, os problemas das equações de transportes de sedimentos, as conexões entre perenidade fluvial e os padrões de vertentes, o papel das soleiras rochosas e tectônicas, o significado documentar histórico-geológico dos alvéolos embutidos, e, o que consideramos como mais importante, ou seja, o da ingenuidade da aplicação de modelos produzidos em bacias localizadas nas altas e médias latitudes e transferidos para os trópicos úmidos. Fato que alertou sobre a natureza peculiar das redes de drenagem instaladas nos ambientes tropicais e que praticamente interfere no rumo do método adotado.

Essas questões pontuadas acima eram de certa forma tratadas nos sistemas teóricos da fase anterior. Entretanto, dúvidas e incertezas pairavam nas discussões geomorfológicas precedentes, devido às limitações da análise empírica, e, somente foram resolvidas, a partir do momento em que se percebeu que, certos eventos e fenômenos da natureza, precisavam ser medidos, monitorados e mensurados, em ensaios que almejavam arremedar os movimentos dinâmicos da paisagem.

\subsection{O período das integrações}

Parece-nos algo meio profético, mas a geomorfologia atual - e a fluvial aí se insere - é caracterizada, ainda que de uma forma embrionária e neófita, por uma preciosa vontade de retorno e recuperação dos métodos e das concepções antigas de trabalhos que foram desenvolvidos nos estágios iniciais de formação dessa disciplina à luz das técnicas modernas de investigação.

Não é uma época fácil para se vislumbrar tendências, muito menos encontrar os vestígios que caracteri- zam o processo de desenvolvimento da geomorfologia fluvial para as próximas décadas. Aqui, deve-se mudar um pouco o foco do campo de um ramo de pesquisa específica, para o contexto geral da ciência geomorfológica com o objetivo de facilitar uma melhor visão de alcance dos contextos. Também não é possível marcar um ponto nítido de mudança, e a transição histórica é totalmente confusa sendo melhor posicionada a partir do fim da década de 1970 e início de 1980.

Não desejamos, ao dizer que se percebe inicialmente um retorno aos trabalhos antigos, fundar o argumento de que as abordagens de Davis, Penck, Gilbert, Powell e King, estarão de volta às pesquisas atuais da geomorfologia em um efervescente debate para os próximos anos. No entanto, concordamos com Ritter (1988), Rhoads e Thorn (1996), Rhoads (2006) e Orme (2002), na ideia de que os estudos geomorfológicos contemporâneos demonstram ligeira tendência de retorno a uma abordagem e enfoque científico, assentado no estilo físico de fazer ciência de Grove Karl Gilbert. Embora estes autores considerem a origem deste retorno como algo ocorrente nas últimas quatro décadas, acreditamos que o início desta tendência melhor se observa nos últimos trinta anos, pelas seguintes razões, a saber:

- Primeiro, a geomorfologia atual em acordo com Rhoads e Thorn (op. cit.), é fortemente dependente de outras ciências naturais, particularmente a Física, a Química e a Biologia, bem como de suas técnicas observacionais e do desenvolvimento de suas formulações teóricas. Qualquer mudança de paradigma nestas disciplinas causa impacto na essência da análise geomórfica, que esta cada vez mais envolvida em uma esfera interdisciplinar. Portanto, o progresso do construto geomorfológico atual depende não somente de uma progressão teórica interna, mas, igualmente, do avanço teórico de outras disciplinas correlatas. Este fato já era visualizado e considerado por Gilbert em sua abordagem física dos aspectos da paisagem, muito presente em seu trabalho de 1914.

- Segundo, há a uma continuidade e dominância que vem se estendendo nos últimos decênios, a partir de uma pequena transição da fase anterior, de um enfoque investigativo orientado no estudo dos processos geomórficos, mesmo os que possuem objetivos de entendimento da evolução histórica da paisagem. Estes estudos, na grande maioria das vezes, degeneram na produção de modelos que 
intencionam repetir os vetores da natureza e as manifestações dinâmicas do fenômeno geomórfico. Aqui, deve-se chamar a atenção para o fato de que os modelos geomorfológicos, devido ao grau de desenvolvimento e maturidade que essa disciplina alcançou ao longo da sua história, não somente resultam na tentativa de repetir determinados vetores da natureza, tal como ocorria no passado e como acontece em outras disciplinas, mas, objetivam comparar e correlacionar os efeitos dos fenômenos modelados com os resultados evidentes da própria natureza. As correlações demonstram as aproximações e os níveis de certeza dos resultados, bem como da capacidade evocativa de explicação da teoria e da operacionalidade do método.

- Terceiro, assim como na visão científica de Gilbert, a pesquisa geomórfica está se cerceando de trabalhos que não levem em consideração o caráter observacional dos eventos e dos significados das heranças, na busca das variáveis para construção do raciocínio geomorfológico. As pesquisas atuais vêm constantemente solicitando a procura de técnicas, que facilitem a observação sistemática e mais acurada dos mecanismos que regem os fenômenos tanto no tempo, quanto no espaço, e, assim é possível visualizar uma quarta tendência na produção desta disciplina, que denota o retorno ao "estilo" científico físico.

Vêm crescendo muito na geomorfologia a aplicação e contextualização dos procedimentos operacionais oriundos dos avanços de instrumentos e aparelhos tecnológicos que possibilitam o aumento da exatidão, tratamento e acurácia dos dados e informações compiladas pelo método. É dessa forma que os satélites e as novas técnicas de sensoriamento remoto, os sistemas de informação geográfica e a cobertura por meio do sistema de posicionamento global (GPS), estão provocando uma revolução na natureza dos dados coletados, e, permitindo aos geomorfológos retornarem ao modo da observação pari passu, que anteriormente ficava na dependência dos vultosos trabalhos de campo. Isso implicou, e, vem implicando, em mudanças significativas nos trabalhos de macro e micro compartimentação geomorfológica, megageomorfologia, tectônica e arranjo estrutural dos terrenos e de análise morfoestrutural e morfoescultural. Portanto, estas quatro características que pontuamos, e, que vêm se exultando seja de forma direta ou indireta nas pesquisas geomorfológicas, denotam a quase imperceptível ideia de se considerar esta disciplina, no retorno a uma dimensão de "análise física", similar à abordagem de Gilbert, que possui forte capacidade de vinculo interdisciplinar com outras ciências. Todavia, esse contexto apresenta-se mais perceptível no âmbito dos estudos processuais entre aqueles que utilizam técnicas modernas e interdisciplinares, oriundas de outros campos científicos.

No entanto, nos enunciados das pesquisas de geomorfologia histórica uma transformação também vem ocorrendo na apreensão da evolução teórica da paisagem - por meio de uma visão cíclica - para algo similar à análise de eventos pontuados de desequilíbrio. Não é mais aconselhável considerar os processos no desenvolvimento do tempo geológico, dentro de uma ótica de mudanças sequenciais, mas sim, em uma representação dinâmica contínua, que se transforma em face das mudanças dos fatores que respondem pelas condições de ambiente da paisagem, localizados em um determinado segmento do território. É dessa forma que as heranças estão sendo solicitadas e recuperadas no conjunto da análise geomórfica, possuindo a cada trabalho, suma importância nas pesquisas de compartimentação topográfica e de feitura de modelos. Assim sendo, é possível também, no âmbito atual da produção geomorfológica, vislumbrar uma tendência que a cada dia ganha maior ímpeto. Trata-se dos estudos que almejam uma aplicação imediata de resultados para efeitos de planejamento do uso e apropriação dos recursos naturais, tendo o relevo como fator de análise e as bacias hidrográficas como unidade de estudo. Esta linha de pesquisa é comumente designada de forma genérica como "geomorfologia antrópica", e/ou "geomorfologia ambiental". Não é algo novo, pois na engenharia hidráulica do século XVII e XVIII os conhecimentos sobre os processos fluviais eram utilizados pelos engenheiros hidráulicos franceses e italianos no planejamento de obras de drenagem em Roma e em Paris. Entretanto, nos últimos tempos e devido, também, ao aprofundamento da urbanização, essa linha emerge com muita força, fazendo forte interação com os conhecimentos advindos da "geologia de engenharia".

Chorley (1969) teve um papel importante no surgimento desta tendência quando cristaliza a ideia, em seu artigo, da bacia hidrográfica como unidade geomórfica 
fundamental de estudo podendo ser considerada, ao mesmo tempo, como unidade topográfica, hidráulica e hidrológica; um sistema físico aberto em termos de entrada de precipitação e radiação solar e de saída de descarga, evaporação e rerradiação solar. Essa visão vem colaborando para a institucionalização da ideia de se tomar o espaço da bacia como unidade de análise para pesquisa e planejamento urbano, regional e espacial, que no fim tem acabado em tentativas superficiais de aplicações de resultados que, na maioria das vezes, são oriundos de estudos mal elaborados do ponto de vista teórico e do método, conforme apontado por Vervloet (2009). Portanto, se é que seja possível conjeturar as tendências atuais da geomorfologia, e em especial o campo de estudo dos processos fluviais, sendo isto uma tarefa difícil e temerária - dadas as características confusas da produção científica contemporânea nesse campo da ciência - ainda que com propriedades de uma penumbra, se percebe um ligeiro retorno, como apontam as características que foram apresentadas acima, à ideia de se tomar a geomorfologia como uma ciência física, fundamentada nos princípios da termodinâmica e análoga a uma visão de sistemas em equilíbrio, que se modificam com base nas transformações das variáveis, de forma a adquirir novos ajustes, ao longo de um desenvolvimento dinâmico, seguido por e dentro de uma sequência temporal. Acreditamos que esses sejam os principais traços que caracterizam essa disciplina, nesta passagem conturbada do século XX para o XXI.

\section{Conclusões}

A evolução dos conhecimentos que originaram a geomorfologia fluvial ocorreu através de um processo contínuo de desenvolvimento conceitual, iniciado na passagem do século XVII ao XVIII. Esse processo foi iniciado após a engenharia hidráulica e a hidrodinâmica atingirem certo grau de evolução conceitual que, a partir do contato com a morfologia fluvial, teve como preocupação central o objetivo de estabelecer um conhecimento disciplinar responsável por explicar o papel dos processos fluviais na explicação da origem da paisagem terrestre. Do certo grau de evolução atingido e do contato com autores preocupados em entender a história geológica da paisagem, a ênfase nos "processos fluviais morfológicos" é estabelecida; consolidando um conhecimento científico que vem originar, no início do século $\mathrm{XX}$, a geomorfologia fluvial.
As etapas históricas que permitiram a evolução dos conhecimentos se deram por meio das aproximações sucessivas, sem que houvesse ruptura epistemológica, conforme Russel (1978). A construção teórica foi, desta forma, elaborada por etapas contínuas, aproveitando-se a capacidade evocativa dos conceitos, sem necessariamente descarta-los em sua noção integral.

Atualmente, a geomorfologia se caracteriza por uma tentativa de integração de suas correntes teóricas, visando construir um sistema mais abrangente possível de explicação do relevo terrestre. Característica que já ocorreu em sua evolução histórica, quando Grove Karl Gilbert almejava explicar o relevo por meio de sistemas teóricos elaborados através dos conhecimentos de diversos campos interdisciplinares.

\section{Referências Bibliográficas}

ABREU, A. A. de. Surrell e as Leis da Morfologia Fluvial. In Craton \& Intracraton - Escritos e Documentos. São José do Rio Preto, São Paulo, IBILCE-UNESP, 1980.

. Análise Geomorfológica: Reflexão e Aplicação. Tese (Livre Docência). Faculdade de Filosofia, Letras e Ciências Humanas - FFLCH, USP, São Paulo, SP, 1982.

BAGNOLD, R. A. Some Aspects of the Shape of River Meanders. Geological Survey Professional Paper, Washington, USA, 282 - E, p. 135 - 144, 1960.

BISWAS, A. K. History of hydrology. North Holland Publishing Company. Holanda, 1970.

BRICE, J. C. Erosion and Deposition in the Loess-Mantled Great Plains Medicine Creek Drainage Basin, Nebraska. Geological Survey Professional Paper, Washington DC, USA, 422 - D, p. 255 - 335, 1964.

Meandering Pattens of the White River in

Indiana - An Analysis. In: MORISAWA, M. (ed.). Fluvial Geomorphology. A Proceedings Volume of the Fourth Annual Geomorphology Symposia Series held at Binghamton, New York, USA, 1973, p. $178-200$.

BRYAN. K. Erosion and sedimentation in the Papayo country, Arizona. U.S. Geol. Sur. Bull., Washington DC, USA, 730, p. 19-90, 1922.

BRUSH JÚNIOR, L. M. Drainage Basins, Channels, and Flow Characteristics of Selected Streams in Central Pennsylvania. Geological Survey Professional Paper, Virginia, USA, 282 - F, 1961 , p. $145-181$. 
BUWALDA, J. P. Intersequent, a new type of stream. (abstract), Geol. Soc. Am. Bull., Washington, USA, vol. 43, p. $228,1932$.

CHRISTOFOLETTI, A. Análise morfométrica de bacias hidrográficas do Planalto de Poços de Caldas (MG). (1970), 215 p. Tese (Livre Docência), Faculdade de Filosofia, Ciências e Letras de Rio Claro, UNESP, Rio Claro, 1970

Geomorfologia Fluvial. São Paulo: Edgard Blücher, 1981, 292 p.

CHORLEY, R. J. The drainage basin as a fundamental geomorphic unit. In: CHORLEY, R. J. (ed.). Water, Earth and Man. London, Methuen, England, 1969, pp. 77-99.

CHORLEY, R., DUNN, A.J. \& BECKINSALE, R.P. The history of the study of landforms. Vol. 01, London: Methuen, England, 1964, $678 \mathrm{p}$.

DAVIS. W. M. The geographical cycle. Geographical Journal, London, England, 14: p. 481-504, 1899.

Sheetfloods and Streamfloods. Geological Soc. Am. Bull, Washington DC, USA, 49, p. 1337-1416, 1938.

. Base level, grade, and peneplain. Journal Geol., Chicago, USA, 1902, 10: p. 77-111.

DEAN. D. R. James Hutton's rôle in the history of geomorphology. In: TINKLER, K. J. (ed.) The History of Geomorphology: from Hutton to Hack. Proceedings of the 19 th Annual Binghamton Geomorphology Symposium, New York, USA, 1989, p. $73-84$.

FRANÇA, G. V. de. Interpretação fotográfica de bacias e de redes de drenagem aplicada a solos da região de Piracicaba. Tese (doutoramento), Escola Superior de Agricultura Luis de Queiroz, Piracicaba, SP, mimeografado 1968, 151 p.

GANDOLFI, N. Bacia do Mogi-Guaçu: morfometria da drenagem, sedimentologia e investigação físico-química. Tese (doutoramento), Escola de Engenharia de São Carlos, UFSC, São Carlos, SP, 1968, 123 p. mais figuras.

GILBERT, G. K. The transportation of debris by running water. U.S. Geol. Surv. Prof. Paper, Washington, USA, 86, 263 p., 1914.

HACK, J. T. Stream-profile analysis and stream-gradient index. Journal of Research of the United States Geological Survey, Arlington, USA, 1973a, v. 1, n 4, pp. 421-429.

Drainage Adjustment in the Appalachians. In: MORISAWA, M. (ed.). Fluvial Geomorphology. A Proceedings Volume of the Fourth Annual Geomorphology Symposia Series held at Binghamton, New York, USA, 1973b, p. 51 - 69.

HICKIN, E. J. Hydraulic Factors Controlling Channel Migration. In DAVIDSON, A. (ed.). Research in Fluvial Systems. Published by W. Nickiling Geo Abstracts LTD. University of East Anglia, England, 1978, p. cap. 03.

HORTON, R. E. Erosional development of streams and their drainage basins: hydrophysical approach to quantitative morphology. Geol. Soc. Amer. Bulletin, Colorado, USA, vol. $56, \mathrm{n}^{\circ} 3$, pp. 275-370, 1945.

KELLER, E. A. e MELHORN, W. N. Bedforms and Fluvial Processes in Alluvial Stream Channel: Selected Observations. In: MORISAWA, M. (ed.). Fluvial Geomorphology. A Proceedings Volume of the Fourth Annual Geomorphology Symposia Series held at Binghamton, New York, USA, 1973, p. 253 - 283.

KING. L. Canons of landscape evolution. Bull. Geol. Soc. of America. New York, Washington, USA, 64 (7), p. 721-752, 1953.

A Geomorfologia do Brasil Oriental. Revista Brasileira de Geografia. Rio de Janeiro, 18 (2), p. 147-266, 1956.

KUHN, T. S. A estrutura das revoluções científicas. Editora Perspectiva, São Paulo, 1998.

LEOPOLD, L. B. e MADDOCK, T. The hydraulic geometry of stream channels and some physiographic implications. $U$. S. Geological Survey Professional Paper, 252, Washington DC, USA, 57 p., 1953.

LEOPOLD, L. B. e LANGBEIN, W. B. The concept of Entropy in Landscape Evolution. U. S. Geological Survey Professional Paper, Washington DC, USA, 500 - A, p. 1 - 20, 1962.

LEOPOLD, L. B. WOLMAN, M. G., MILLER, J. P. Fluvial Processes in Geomorphology. W. H. Freeman \& Co., San Francisco, USA, 1964, 522 p.

Flow Resistance in Sinuous or Irregular Channels. Geological Survey Professional Paper, Washington DC, USA, 282 - D, p. 111 - 134, 1960

LEOPOLD, L. B. e MILLER, J. P. Ephemeral Streams Hydraulic Factors and Their Relation to the Drainage Net. U. S. Geological Survey Professional Paper, Washington DC, USA, 282 - A, p. 1 - 37, 1956.

LEOPOLD, L. B. e WOLMAN, M. G. River Channel Pattens: Braided, Meadering and Straight. U. S. Geological Survey Professional Paper, Washington DC, USA, 282 - B, p. 39 - 85, 1957.

MORISAWA. M. Rivers - Forms and process. (Série Geomorphology Texts 07), New York: Longman Inc., 1985, 221 p. 
ORME. A. R. Shifting paradigms in geomorphology: the fate of research ideas in an educational context. Geomorphology, $\mathrm{n}^{\circ} 47$, (2002), p. 325-342.

PENCK, W. Morphological analysis of land forms. Tradução e edição H. CZECH e K.C. BOSWELL. London, England, Macmillan, 1953, 429 p.

RHOADS, B. L. The Dynamic Basis of Geomorphology Reenvisioned. Annals of the Association of American Geographers, Washington DC, 96 (1), p. 14-30, 2006.

RHOADS, B. L. e THORN, C. E. Observation in Geomorphology. In: RHOADS, B. L.; THORN. C. E. The scientific nature of geomorphology. Ed. Chichester, U.K.: Wiley, 1996, p. 21-56.

RITTER, D. F. Landscape analysis and the search for geomorphic unity. Geological Society of America, Washington DC, USA, v. 100, February 1988, p. 160-171.

ROUSE, H. e INCE, S. History of hydraulics. New York: Dover Publications, 1957, 269 p.

RUSSEL, B. Ensaios escolhidos. Coleção Os Pensadores. São Paulo: Abril Cultural, 1978.

SMART, J. S. The Random Model in Fluvial Geomorphology. In: MORISAWA, M. (ed.). Fluvial Geomorphology. A Proceedings Volume of the Fourth Annual Geomorphology Symposia Series held at Binghamton, New York, USA, 1973, p. $27-49$.

SCHUMM, S. A. e KHAN, H. R. Experimental Study of Channel Pattens. Geological Society of América Bulletin, Colorado, USA, v. 83, p. 1755 - 1770, 1972.

SCHUMM, S. A. Evolution of drainage systems and slopes in badlands of Perth Amboy. U. S. Geol. Soc. Amer. Bulletin, Colorado, USA, vol. 67, pp. 597-646, 1956.

The Shape of Alluvial Channels in Relation to Sediment Type. U. S. Geological Survey Professional Paper, Washington DC, USA, 352-5, p. 17-30, 1960.

. The Effect of Sediment Characteristics on Erosion and Deposition in Ephemeral Stream Channels. U. S. Geological Survey Professional Paper, Washington DC, USA, 352 - C, p. $31-70,1961$.
Evolution and Response of the Fluvial System, Sedimentologic Implications. In ETHRIDGE, F. G. e FLORES, R. M. (ed.). Recent and ancient nonmarine depositional environments: Models for exploration. Society of Economic Paleontologist and Mineralogists. Special Publication 31, Tulsa, Oklahoma, USA, 1981, p. 19-29.

STRAHLER, A. N. Hypsometric (area-altitude) analysis of erosional topography. Geol. Soc. Amer. Bulletin, Colorado, USA, vol. 63, p. 1117-1142, 1952.

- Dimensional analysis applied to fluvialy eroded landforms. Bull. Geol. Soc. Am. Colorado, USA, 69, p. 279 $-300,1958$.

TRICART. J. Os Tipos de Leitos Fluviais. Notícia Geomorfológica, Campinas, ano VI, $\mathrm{n}^{\circ}$ 11, junho de 1966, p. $41-49,1966$.

VERVLOET, R. J. H. M. Condicionantes morfológicos e estruturais na dinâmica fluvial da bacia hidrográfica do Rio Benevente - Espírito Santo. 2009, 415 p. (Dissertação de mestrado), Programa de Pós-graduação em Geografia Física, FFLCH, USP, São Paulo, 2009.

VIEIRA DA SILVA, R. C. V. da.; MASCARENHAS, F. C. B.; MIGUEZ. M. G. Hidráulica Fluvial. Vol. 01, $2^{\mathrm{a}}$ ed., Rio de Janeiro: COPPE/UFRJ, 2007, 306 p.

VIEIRA DA SILVA, R. C. V. da.; JÚNIOR, G. W. Hidráulica Fluvial. Vol. 02, Rio de Janeiro: COPPE/UFRJ, 2005, 256 p.

WOLMAN, M. G. e LEOPOLD, L. B. River Flood Plains: Some Observations On Their Formation. U. S. Geological Survey Professional Paper, Washington DC, USA, 282 - C, 1957, p. $87-109$.

WOLMAN, M. G. e BRUSH JÚNIOR, L. M. Factors Controlling the Size and Shape of Stream Channels in Coarse Noncohesive Sands. U. S. Geological Survey Professional Paper, Washington DC, USA, 282 - G, p. 183 - 210, 1961.

YANG, C. T. e STALL, J. B. Unit Stream Power in Dynamic Stream Systems. In: MORISAWA, M. (ed.). Fluvial Geomorphology. A Proceedings Volume of the Fourth Annual Geomorphology Symposia Series held at Binghamton, New York, USA, 1973, p. $285-287$. 